"This is a post-peer-review, pre-copyedit version of an article published in Biotechnology Letters. The final authenticated version is available online at: https://doi.org/10.1007/s10529-018-2585-5"

This version is subjected to Springer Nature terms for reuse that can be found at: $h$ ttps://www.springer.com/gp/openaccess/authors-rights/aam-terms-v1 


\section{Purification of active recombinant human histone deacetylase 1 (HDAC1) overexpressed in Escherichia coli}

Alessandra Stefan, ${ }^{1,3, \#}$ Natalia Calonghi, ${ }^{1, \#}$ Fabrizio Schipani, ${ }^{1}$ Fabrizio Dal Piaz, ${ }^{2}$ Giorgio Sartor, ${ }^{1}$ Alejandro Hochkoeppler ${ }^{1,3, *}$

1 Department of Pharmacy and Biotechnology, Viale Risorgimento 4, 40136 Bologna (Italy)

2 Department of Medicine, University of Salerno, Via Giovanni Paolo II 132, 84084 Fisciano SA (Italy)

3 CSGI, University of Firenze, Via della Lastruccia 3, 50019 Sesto Fiorentino FI (Italy)

\# A S and N C contributed equally to this work.

*To whom correspondence should be addressed:

Prof. Alejandro Hochkoeppler

Department of Pharmacy and Biotechnology

University of Bologna

Viale Risorgimento 4

40136 Bologna

Italy

Tel.: ++ 390512093671

Fax: ++ 390512093673

e-mail: a.hochkoeppler@unibo.it

Running Title: Overexpression and purification of recombinant HDAC1.

Type of paper: Microbial and Enzyme Technology 


\section{ABSTRACT}

4 Objective We attempted to overexpress Human Histone Deacetylase 1 (HDAC1) in Escherichia coli.

5 Results A synthetic gene coding for HDAC1, and optimised for E. coli codon usage, was cloned into pBADHisB, generating pBAD-rHDAC1. This construct was used to transform E. coli TOP10, and the target protein was overexpressed and partially purified. According to its elution volume from a

8 Superdex 200 column, the partially purified rHDAC1 was obtained in aggregated form, i.e. as an 9 octamer. The dissociation of octameric HDAC1 was tested using several agents, among which sodium dodecyl sulfate was competent in partially dissociating rHDAC1 aggregates. When the enzyme activity was tested in vitro using ${ }^{3} \mathrm{H}$-acetyl-labelled histones both protein samples, aggregated and dissociated, were active. Hence, our results suggest that E. coli represents an alternative system

13 for the production of the recombinant HDAC1.

Conclusions We described a procedure for the overexpression in E. coli of recombinant HDAC1, the purification of which in active form can be successfully performed, although yielding an octameric aggregate.

Key words: Escherichia coli; heterologous expression; human histone deacetylase 1 (HDAC1); protein dissociation; protein purification. 


\section{INTRODUCTION}

3 Histone deacetylases (HDACs) are specifically responsible for the deacetylation of lysine residues at

4 the N-terminal regions of the core histones (H2A, H2B, H3 and H4). In addition, HDACs may deacetylate other non-histone proteins and thus are involved in several cellular processes (e.g. differentiation, apoptosis, cancer development).

To date, human histone deacetylases belonging to all three known classes (class I: HDAC1, HDAC2, HDAC3, HDAC8; class II: HDAC4, HDAC5, HDAC6, HDAC7, HDAC9, HDAC10; class III: HDAC11) have been produced using the baculovirus-insect cell expression system. However, all these recombinant proteins were generally expressed as GST/His/FLAG-tagged proteins with limited yield and high costs. Alternatively, the heterologous expression system based on Escherichia coli provides several advantages, such as the simple and well-known genetic manipulation, the high cell density achievable, the short time for cultivation and the cheapness of substrates. Despite these advantages, the use of $E$. coli as an alternative expression system for HDACs has been limited. Recently, the full length HDAC8, belonging to the class I, was produced using E. coli BL21(DE3) cells. In particular, the protein was fused either to GST or His-tag at the N-terminal and the overexpression was triggered by the addition of IPTG to the culture medium (Feng et al. 2011). Both recombinant proteins, mostly recovered in the insoluble fraction, were active after purification using GST or Ni-NTA resin columns, respectively, followed by Source Q and Superdex-200 columns.

The expression of His-tagged HDAC1 in HEK293 cells transformed with the pcDNA3.1 vector was attempted ( $\mathrm{Li}$ et al. 2004). In this case, the yield of recombinant protein was very low, albeit the recovered enzyme was shown to be active. To investigate the role of in vivo and in vitro phosphorylation at S421 and S423 sites, the gene coding for HDAC1 was recently cloned into the pET21b vector and the enzyme was overexpressed as His-tagged protein in E. coli BL21(DE3) (Karwowska-Desaulniers et al. 2007). However, the production of HDAC1 with high yields has not been described yet. Nevertheless, recombinant HDAC1 is commercially available, although with low 
1 purity and at high cost. To improve the efficiency of recombinant HDAC1 production, we report here

2 on a procedure for the production of this enzyme devoid of any tag, using E. coli as the expression 3 host.

\section{MATERIALS AND METHODS}

\section{Bacterial strain, plasmid and media}

Escherichia coli TOP10 was used for the expression of recombinant HDAC1 (rHDAC1). A synthetic gene, optimised for E. coli codon usage using the software Leto ${ }^{\circledR}$ (Entelechon GmbH, Germany), was cloned into the pBADHisB expression vector (Invitrogen, USA), using the NcoI and PstI restriction sites, yielding the recombinant pBAD-rHDAC1 plasmid. E. coli TOP10 competent cells were transformed by electroporation with $20 \mathrm{ng}$ of the recombinant construct, and transformants were selected on LB agar plates containing ampicillin $(100 \mu \mathrm{g} / \mathrm{mL})$. Bacterial cultures were grown in LB medium $(10,5$, and $10 \mathrm{~g} / \mathrm{L}$ of tryptone, yeast extract, and $\mathrm{NaCl}$, respectively) supplemented with ampicillin $(100 \mu \mathrm{g} / \mathrm{mL})$.

\section{Optimization of protein expression}

Single colonies of $E$. coli TOP10/pBAD-rHDAC1 were grown overnight at $37{ }^{\circ} \mathrm{C}$ in $5 \mathrm{~mL}$ of

LB/ampicillin. The pre-cultures accordingly obtained were diluted (1:250) in $20 \mathrm{~mL}$ of fresh medium, and grown for $8 \mathrm{~h}$ at $37^{\circ} \mathrm{C}$, under constant shaking $(200 \mathrm{rpm})$. The expression of the target protein was tested as a function of temperature $\left(30\right.$ or $\left.37^{\circ} \mathrm{C}\right)$, of the concentration of arabinose $(1.3$ or 13 $\mathrm{mM})$ and of induction time (2.5, 6 and $15 \mathrm{~h})$. To analyse the expression of rHDAC1, cells pellets were resuspended in 10\% SDS (m/v), $10 \mathrm{mM} \beta$-mercaptoethanol, 30\% glycerol (v/v), $0.2 \mathrm{M}$ Tris$\mathrm{HCl} \mathrm{pH} 6.8,0.05 \%$ bromophenol blue $(\mathrm{m} / \mathrm{v})$ and boiled for $5 \mathrm{~min} .18 \mu \mathrm{L}$ of each sample were subjected to SDS-PAGE in $10 \%$ polyacrylamide gels. 
1 After growing a culture at $37{ }^{\circ} \mathrm{C}$ for $8 \mathrm{~h}$, the expression of rHDAC1 was induced with $1.3 \mathrm{mM}$

2 arabinose at $30{ }^{\circ} \mathrm{C}$ for $15 \mathrm{~h}$. The cells suspension ( $3 \mathrm{~L}$ ) was centrifuged and the pellets were

3 resuspended in $40 \mathrm{~mL}$ of buffer A $(50 \mathrm{mM}$ Tris- $\mathrm{HCl} \mathrm{pH} 8,50 \mathrm{mM} \mathrm{NaCl}, 1 \mathrm{mM}$ EDTA, $2.5 \mathrm{mM}$

4 DTT) supplemented with $1 \mathrm{mM}$ phenylmethylsulfonylfluoride (PMSF). Cells were homogenized

5 using a cold potter, then sonicated on ice ( 7 cycles, $15 \mathrm{sec}$ pulses with $15 \mathrm{sec}$ intervals, at $18 \mathrm{~W}$ for 2

$6 \mathrm{~min})$. Soluble proteins were recovered by centrifugation at 10,000xg for $30 \mathrm{~min}$. Protein

7 concentration was then determined according to Bradford (Bradford 1976).

\section{rHDAC1 purification}

After filtration, the protein extract $(40 \mathrm{~mL})$ was loaded onto a Q-Sepharose FF column $(1.6$ x $25 \mathrm{~cm}$, $50 \mathrm{~mL}$ volume) equilibrated with buffer A. Following a washing step with the same buffer, the elution was performed by a linear 50-600 $\mathrm{mM} \mathrm{NaCl}$ gradient. Eluted fractions, diluted 1:2 with buffer B (buffer A containing 40\% glycerol), were subjected to SDS-PAGE analysis. The best fractions were pooled, diluted in buffer $\mathrm{C}(50 \mathrm{mM}$ Tris- $\mathrm{HCl} \mathrm{pH} 8,1 \mathrm{mM}$ EDTA, 20\% glycerol $)$ and concentrated by ultrafiltration. The resulting sample was loaded onto a HiTrap Heparin affinity column (5 mL, GE Healthcare, USA) equilibrated with buffer D (50 mM Tris- $\mathrm{HCl} \mathrm{pH} 8,50 \mathrm{mM} \mathrm{NaCl}, 1 \mathrm{mM}$ EDTA, $20 \%$ glycerol). After washing, a linear $50-800 \mathrm{mM} \mathrm{NaCl}$ gradient was applied and fractions of 0.8 $\mathrm{mL}$ were collected. The flow-through was concentrated and then applied to a poly-L-lysine agarose (Sigma-Aldrich, USA) affinity column $(1.5 \times 5 \mathrm{~cm}, 8 \mathrm{~mL}$ volume) previously equilibrated with buffer D. The elution was performed with a linear gradient from $50 \mathrm{mM}$ to $1 \mathrm{M} \mathrm{NaCl}$ and the presence of rHDAC1 was evaluated by SDS-PAGE. The final purification step was performed with a Superdex 200 column $(1.6 \times 70 \mathrm{~cm})$, previously calibrated with Broad-Molecular-Weight protein standards (GE Healthcare, USA), and equilibrated with $50 \mathrm{mM}$ Tris- $\mathrm{HCl} \mathrm{pH}$ 8, $150 \mathrm{mM} \mathrm{NaCl}, 1 \mathrm{mM}$ EDTA, 20\% glycerol, $2.5 \mathrm{~mm}$ DTT.

\section{Mass spectrometry}

Elution of proteins from acrylamide gels, trypsin digestion, and separation of peptides were performed as previously described (Shevchenko et al. 2007; Conte et al. 2012). 


\section{Dissociating agents}

2 In order to obtain rHDAC1 in monomeric form, different conditions and dissociating agents were

3 tested: aliquots of purified $\operatorname{rHDAC} 1(2.5 \mu \mathrm{g})$ were incubated at room temperature for $1 \mathrm{~h}$ in the

4 presence of each agent. The samples were conditioned with native sample buffer (40\% v/v glycerol,

$5 \quad 0.4 \mathrm{M}$ Tris- $\mathrm{HCl} \mathrm{pH} 6.8,0.05 \%$ bromophenol blue), then loaded on native polyacrylamide gels (7.5

6 and $4 \%$ acrylamide for running and stacking gel, respectively). Additional samples, prepared by

7 mixing $5 \mu \mathrm{g}$ of $\mathrm{rHDAC} 1$ with each dissociating agent in a volume of $100 \mu \mathrm{L}$, were loaded onto

8 Amicon Ultracel 100,000 NMWL filters (Millipore, USA), and centrifuged for $45 \mathrm{~s}$ at 14,000xg. Both

9 eluate and retentate fractions were subjected to SDS-PAGE analysis (10\% acrylamide).

10 Preparation of $\left[{ }^{3} \mathrm{H}\right]$ acetyl histones and assay of HDAC1 activity

11 To obtain $\left[{ }^{3} \mathrm{H}\right]$ acetyl-labelled histones as the substrate for the HDAC1 assay, $1 \times 10^{7} \mathrm{HT} 29$ cells were incubated in $30 \mathrm{~mL}$ of medium containing $0.5 \mathrm{mCi} / \mathrm{mL}\left[{ }^{3} \mathrm{H}\right]$ acetate for $1 \mathrm{~h}$, and the labeled histone fraction was immediately extracted. Cells were harvested using $0.11 \%$ trypsin and $0.02 \%$ EDTA, washed twice with $10 \mathrm{mM}$ sodium butyrate in PBS, and nuclei were isolated (Amellem et al. 1996). Sodium butyrate $(5 \mathrm{mM})$ was added to nuclear isolation buffer to prevent histone deacetylation. The nuclear pellet was suspended in $0.1 \mathrm{~mL}$ of ice-cold water using a Vortex mixer, and concentrated $\mathrm{H}_{2} \mathrm{SO}_{4}$ was added to the suspension to give a final concentration of $0.4 \mathrm{M}$. After incubation at $4{ }^{\circ} \mathrm{C}$ for $1 \mathrm{~h}$, the suspension was centrifuged for $5 \mathrm{~min}$ at 14,000xg, and the supernatant was taken and mixed with $1 \mathrm{~mL}$ of acetone. After overnight incubation at $-20{ }^{\circ} \mathrm{C}$, the coagulate material was collected by microcentrifugation and air-dried. This acid-soluble histone fraction was dissolved in 50

$21 \mu$ l of water. Protein concentration was determined by the Bradford assay (Bradford 1976). HDAC1 activity was estimated in $50 \mu \mathrm{l}$ of a reaction mixture containing 1.5 or $2.5 \mu \mathrm{g}$ HDAC1, $\left[{ }^{3} \mathrm{H}\right]$ acetate-labeled HT29 histones (12,000 dpm) dissolved in HDA buffer (20 mM Tris-HCl, pH 8.0, 150 $\mathrm{mM} \mathrm{NaCl}, 10 \%$ glycerol) at $37{ }^{\circ} \mathrm{C}$ for $2 \mathrm{~h}$. The reaction was stopped by the addition of $50 \mu \mathrm{l}$ of $1 \mathrm{M}$ 
1 and the solvent layer was taken into $5 \mathrm{~mL}$ of toluene scintillation solution for the determination of 2 radioactivity.

3

\section{RESULTS AND DISCUSSION}

\section{Expression in E. coli}

We attempted the heterologous expression of the human histone deacetylase 1 (HDAC1) in a prokaryotic system. The full-length human HDAC1, GST/His or FLAG-tagged, was produced in baculovirus infected insect cells (Hassig et al. 1997; Hassig et al. 1998). Recently, the expression of the whole human HDAC1 protein in mammalian cells has been achieved (Li et al. 2004). However, in this study, the recombinant HDAC1 was obtained as His-tagged protein (at the N-terminal). So far, several attempts have been made to use microbial expression hosts, like Pichia pastoris and Escherichia coli, but all the systems tested were unsuccessful. The only mammalian histone deacetylase expressed in E. coli was HDAC8 (Feng et al. 2011; Hu et al. 2000): the coding sequence, cloned into pET21b plasmid, was expressed as His-tagged protein using BL21(DE3) cells after induction with IPTG. The recombinant HDAC8-his protein, after purification by nickel affinity column, was found to be active despite the absence of post-translational modifications.

In view of these considerations, we have attempted to express recombinant HDAC1 in E. coli. To this aim, the synthetic gene, optimised for E. coli codon usage (Supplementary Fig. 1), was cloned into the tightly regulated vector, $\mathrm{pBADHisB}$, which contains the araBAD promoter (Guzman et al. 1995). In order to obtain rHDAC1 without any additional sequence, the cloning was performed using proper restriction sites ( $N c o$ I and $P$ st I $)$ to eliminate the N-terminal histidine tag eventually conferred by the vector.

Preliminary experiments were performed in small shake-flasks to test different conditions of growth and induction (e.g. time/temperature of growth and inducer concentration) in order to identify the optimal procedure for the heterologous expression. In particular, we tested two different inducer 
concentrations, 1.3 and $13 \mathrm{mM}$, and two temperatures of induction, 30 and $37^{\circ} \mathrm{C}$. As shown in Fig. 1A (lane 1 and 2), the band corresponding to rHDAC1 was detectable, albeit weak, on denaturing gels, independently of the growth temperature. A similar independence was observed using 1.3 or 13 $\mathrm{mM}$ arabinose as inducer (data not shown). To prevent the possible production of protein aggregates (e.g. inclusion bodies) and to avoid cellular stress in response to the induction, we decided to induce the overexpression of $\mathrm{HDAC} 1$ at $30{ }^{\circ} \mathrm{C}$ with $1.3 \mathrm{mM}$ arabinose, when bacterial populations reached an $\mathrm{OD}_{600}$ equal to $0.8-0.9$. After $15 \mathrm{~h}$ induction at $30{ }^{\circ} \mathrm{C}$, cells pellets were harvested and used for protein extraction.

\section{FIGURE 1}

We determined the growth kinetics of $E$. coli TOP10 populations containing the pBAD-rHDAC1 or the $\mathrm{pBAD}$ vector, under non-inducing or inducing conditions. The addition of arabinose $(5 \mathrm{~h}$ after the inoculum) to induce the expression of rHDAC1 did adversely affect the biomass yield of TOP10/pBAD-rHDAC1 (Fig. 1B), most likely due to a weak toxic effect of the recombinant protein.

\section{Purification of rHDAC1}

We used four chromatographic steps to purify rHDAC1 (see Methods and Supplementary Fig.s 2-4). Starting from about $10 \mathrm{~g}$ of wet biomass the final recovery was equal to $2.5 \mathrm{mg}$ of purified $\mathrm{rHDAC} 1$. Unfortunately, rHDAC1 was obtained in aggregated form, as an octamer. According to the elution volume of the protein from the gel filtration column (Fig. 2A), corresponding to a $\mathrm{K}_{\mathrm{av}}$ of 0.155 , the molecular mass of the recombinant protein was estimated equal to $470 \mathrm{kDa}$, whereas the expected mass is $55.1 \mathrm{kDa}$. The gel filtration peak containing fractions 8-15 (Fig. 2A) did contain HDAC1 as was confirmed by SDS-PAGE (Fig. 2B), and by mass spectrometry (Table 1).

\section{TABLE 1, FIGURE 2}

Although in aggregated form, the recombinant protein was very stable and has not been shown to be susceptible to proteolysis. In particular, $5 \mu \mathrm{g}$ of purified rHDAC1 were incubated at $4{ }^{\circ} \mathrm{C}$ and $37{ }^{\circ} \mathrm{C}$ for $3 \mathrm{~h}$, then samples were analysed by SDS-PAGE. As shown in Fig. 2C, only a single band 
1 corresponding to rHDAC1 is visible, indicating the absence of degradation and high stability of the

2 protein.

\section{Protein dissociation}

4 As previously mentioned, gel filtration chromatography showed that rHDAC1 was produced as a

5 high molecular mass aggregate. Before testing its activity, we tried to dissociate this protein aggregate

6 using several dissociating agents. In particular, the effect of chaotropic species, weak kosmotropes,

7 amino acids, reducing or denaturing agents, detergents, alcohols, and saturated fatty acids was tested

8 (Table 2).

\section{TABLE 2}

Preliminary information about the aggregation state of purified rHDAC1 was obtained by native electrophoresis, performed in the absence of denaturing or reducing agents. Under these conditions, high molecular mass complexes are inhibited from entering the gel. As shown in Fig. 3A, rHDAC1 was able to migrate further in native gels only after pre-treatment with $2 \%(\mathrm{w} / \mathrm{v}) \mathrm{SDS}$, while the incubation with several other agents was ineffective.

\section{FIGURE 3}

A detailed screening of dissociating agents was then performed with a simple and rapid assay: an aliquot of purified rHDAC1 was incubated with each agent at room temperature for $1 \mathrm{~h}$, then samples were subjected to ultrafiltration using disposable cells with a molecular weight cut-off (100 kDa) able to discriminate between monomeric $(55 \mathrm{kDa})$ or aggregated proteins (> dimeric, $110 \mathrm{kDa})$. Samples $(100 \mu \mathrm{L})$ were centrifuged for $45 \mathrm{~s}$ at $14,000 \mathrm{xg}$, then aliquots of the protein retained over the membrane (aggregates) and protein passed through the ultrafilter (monomeric form) were analysed by SDS-PAGE. Interestingly, the anionic detergent SDS was the only agent able to dissociate rHDAC1 aggregates to monomers (lane 4, Fig. 3B), in agreement with the observations obtained with native polyacrylamide gels. Unfortunately, the effect of SDS was incomplete and a significant amount of aggregated protein was still detectable in the retentate fraction. 
1 We also analysed different SDS concentrations (ranging from 0.002 to $2 \% \mathrm{~m} / \mathrm{v}$, corresponding to

2 concentrations from 0.069 to $69 \mathrm{mM}$ ) in order to determine the smallest able to partially dissociate

3 rHDAC1 complexes. This dissociative effect was evident down to concentrations equal to $0.05 \%$

4 (corresponding to $1.75 \mathrm{mM}$, Fig. 3C), while lower concentrations did not trigger dissociation (data not shown). These observations are in excellent agreement with the dissociation action exerted by SDS (tested at concentrations from 0.13 to $10 \mathrm{mM}$ ) towards carmin (Rao and Prakash 1993). The minimal SDS concentration able to dissociate carmin was indeed evaluated as equal to $1.6 \mathrm{mM}$ (Rao and Prakash 1993), a value very close to that reported here as effective in rHDAC1 dissociation, i.e. $1.75 \mathrm{mM}$.

\section{Activity assays}

To assess rHDAC1 activity, the aggregated enzyme was assayed using $\left[{ }^{3} \mathrm{H}\right]$ acetyl histones as substrate. The amount of $\left[{ }^{3} \mathrm{H}\right]$ acetic acid released from the histones was observed to linearly depend on the rHDAC1 concentration in the reaction mixture (Fig. 4).

\section{FIGURE 4}

A small, but significant, release of $\left[{ }^{3} \mathrm{H}\right]$ acetic acid was detected in the absence of rHDAC1, independently of the addition of SDS to the reaction mixture (Fig. 4). However, it should also be noted that the extent of this unspecific activity accounts for 3-5\% only of the activity determined in the presence of enzyme (Fig. 4). We did also compare the activity exerted by $1.5 \mu \mathrm{g}$ of aggregated or monomeric rHDAC1, and we observed similar substrate conversion, i.e. we detected $355 * 10^{3}$ and $275 * 10^{3} \mathrm{dpm} / \mathrm{mg}$ histones in the presence of octameric and monomeric enzyme, respectively.

\section{CONCLUDING REMARKS}

We reported here a procedure for the overexpression of HDAC1 in E. coli. The protein of interest was partially purified, although as an octamer. By appropriate screens, we identified SDS as an agent able to partially dissociate this aggregated form of recombinant HDAC1. When assayed, we detected significant deacetylase activity exerted by rHDAC1, both in aggregated and dissociated form. In 
1 particular, the activity exerted by the aggregated enzyme (Fig. 4) is very similar to the catalytic action

2 reported for rHDAC1 expressed in mammalian cells (Li et al. 2004). Indeed, our HDAC1 preparation

3 and the enzyme expressed in mammalian cells were both assayed with labelled histones, and yielded

4 comparable substrate conversions: i) we incubated, at $37{ }^{\circ} \mathrm{C}$ for $2 \mathrm{~h}, 1.5 \mu \mathrm{g}$ of enzyme and $3.6 \mu \mathrm{g}$ of

5 tritiated histones (featuring $5600 \mathrm{cpm}$ ), and we observed, under these conditions, the conversion of

$618 \%$ of substrate; ii) when $1 \mu \mathrm{g}$ of the enzyme produced in mammalian cells was incubated at $37^{\circ} \mathrm{C}$

7 for $1 \mathrm{~h}$ in the presence of labelled histones, the amount of radioactive product (acetate) was

8 determined as equal to $18 \%$ of substrate (( $\mathrm{Li}$ et al. 2004). These assays suggest that the activity of

9 our octameric rHDAC1 is slightly lower than the recombinant deacetylase isolated from mammalian

10 cells. Accordingly, E. coli seems to be a suitable host for the production of recombinant HDAC1.

SUPPORTING INFORMATION

\section{Supplementary Figure 1}

Sequence of the synthetic optimised rHDAC1 gene. The NcoI and PstI restriction sites, used for the cloning into pBADHisB, are underlined. The ATG start codon in shown in bold.

\section{Supplementary Figure 2}

(A) Purification of rHDAC1 by anion exchange chromatography (Q-sepharose FF column, $50 \mathrm{~mL}$ ).

(B) SDS-PAGE (10\% polyacrylamide) of eluted fractions. Lane M: molecular mass markers (116, washing fractions; numbered lanes: eluted fractions.

\section{Supplementary Figure 3}

(A) HiTrap Heparin affinity chromatography of rHDAC1 (5 mL column). (B) SDS-PAGE (10\% polyacrylamide) of eluted fractions. Lane M: molecular mass markers (116, 66, 45, 35, $25 \mathrm{kDa})$; lane lanes: eluted fractions. 


\section{Supplementary Figure 4}

2 (A) Poly-lysine affinity chromatography of rHDAC1 (8 mL column). (B) SDS-PAGE (10\%

3 polyacrylamide) of eluted fractions. Lane M: molecular mass markers (116, 66, 45, 35, $25 \mathrm{kDa})$; lane

4 I: sample of pooled fractions (input); FT: flow-through fraction; W: washing fraction; numbered 5 lanes: eluted fractions.

6

\section{REFERENCES} stress. Exp Cell Res 227:106-115.

1. Amellem O, Stokke T, Sandvik JA, Pettersen EO (1996) The retinoblastoma gene product is reversibly dephosphorylated and bound in the nucleus in S and G2 phases during hypoxic

2. Bradford MM (1976) A rapid and sensitive method for the quantitation of microgram quantities of protein utilizing the principle of protein-dye binding. Anal Biochem 72:248254. favors in vivo assembly of the Pol III catalytic core. Arch Biochem Biophys 523:135-143.

3. Conte E, Vincelli G, Schaaper RM, Bressanin D, Stefan A, Dal Piaz F, Hochkoeppler A (2012) Stabilization of the Escherichia coli DNA polymerase III $\varepsilon$ subunit by the $\theta$ subunit

4. Feng JH, Jing FB, Fang H, Gu LC, Xu WF (2011) Expression, purification, and Snitrosylation of recombinant histone deacetylase 8 in Escherichia coli. Biosci Trends 5:1722.

5. Guzman LM, Belin D, Carson MJ, Beckwith J (1995) Tight regulation, modulation, and high- 

4130.

3

6. Hassig CA, Fleischer TC, Billin AN, Schreiber SL, Ayer DE (1997) Histone deacetylase activity is required for full transcriptional repression by mSin3A. Cell 89:341-347.

6

7. Hassig CA, Tong JK, Fleischer TC, Owa T, Grable PG, Ayer DE, Schreiber SL (1998) A role for histone deacetylase activity in HDAC1-mediated transcriptional repression. Proc Natl Acad Sci USA 95:3519-3524.

8. Hu E, Chen Z, Fredrickson T, Zhu Y, Kirkpatrick R, Zhang GF, Johanson K, Sung CM, Liu R, Winkler J (2000) Cloning and characterization of a novel human class I histone deacetylase that functions as a transcription repressor. J Biol Chem 275:15254-15264.

9. Karwowska-Desaulniers P, Ketko A, Kamath N, Pflum MKH (2007) Histone deacetylase 1 phosphorylation at S421 and S423 is constitutive in vivo, but dispensable in vitro. Biochem Biophys Res Commun 361:349-355.

10. Li J, Staver MJ, Curtin ML, Holms JH, Frey RR, Edalji R, Smith R, Michaelides MR, Davidsen S, Glaser KB (2004) Expression and functional characterization of recombinant human HDAC1 and HDAC3. Life Sci 74:2693-2705. 
11. Rao KS, Prakash V (1993) Interaction of sodium dodecyl sulfate with multi-subunit proteins. A case study with carmin. J Biol Chem 268:14769-14775.

12. Shevchenko A, Tomas H, Havlis̃ J, Olsen JV, Mann M (2007) In-gel digestion for mass spectrometric characterization of proteins and proteomes. Nat Protoc 1:2856-2860.

\section{FIGURE LEGENDS}

\section{FIGURE 1}

(A) SDS-PAGE of total proteins extracted from E. coli TOP10/pBAD-rHDAC1 cultures. Lane M: protein molecular mass markers (ThermoFisher Scientific). Lane NI: proteins extracted from not induced cultures. Lanes 1 and 2: proteins extracted from cultures induced with $1.3 \mathrm{mM}$ arabinose for $15 \mathrm{~h}$ at 30 or $37^{\circ} \mathrm{C}$, respectively. The arrow indicates the band corresponding to recombinant HDAC1 (approximately $55 \mathrm{kDa}$ ). (B) Kinetics of growth of E. coli TOP10 cultures containing the pBAD empty vector (triangles) or the pBAD-rHDAC1 vector (squares) under non-inducing (empty symbols) or inducing (filled symbols) conditions, respectively. Cultures were grown in LB medium at $37{ }^{\circ} \mathrm{C}$ before induction, then the temperature was shifted to $30{ }^{\circ} \mathrm{C}$ after the addition of $1.3 \mathrm{mM}$ arabinose.

\section{FIGURE 2}

(A) Purification of rHDAC1. Gel filtration chromatographic profile (Superdex 200 column) of rHDAC1 after anion exchange and affinity chromatographies (HiTrap Heparin followed by a PolyL-lysine column). The volume of each collected fraction was $0.9 \mathrm{~mL}$. (B) SDS-PAGE (10\% polyacrylamide) of eluted gel filtration fractions. Lane M: molecular mass markers (116, 66, 45, 35, 
$25 \mathrm{kDa}$ ); lane I: sample of pooled fractions (input); numbered lanes: eluted fractions. (C) Stability of rHDAC1. Lane M: molecular mass markers; lanes 1-2: purified rHDAC1 incubated for $3 \mathrm{~h}$ at 4 and $37{ }^{\circ} \mathrm{C}$, respectively. The arrow indicates the band corresponding to recombinant HDAC1 (55 kDa). (1)

\section{FIGURE 3}

(A) Analysis of protein aggregates by native gel electrophoresis. Lanes 1 and 9: rHDAC1 incubated with 2\% SDS; lanes 2-8 and 10-17: incubation with $500 \mathrm{mM} \mathrm{KCl,} 500 \mathrm{mM} \mathrm{LiCl,} 200 \mathrm{mM} \mathrm{MgCl}$, $200 \mathrm{mM} \mathrm{CaCl}_{2}, 200 \mathrm{mM} \mathrm{SrCl} 2,1 \mathrm{M}$ urea, $10 \mathrm{mM} \beta$-mercaptoethanol, $1 \%$ Triton $\mathrm{X}-100,1 \%$ Tween 20, $2 \%$ ethanol, 2\% 2-propanol, 1.5\% 1-butanol, 0.6\% 1-pentanol, $200 \mathrm{mM}$ arginine, and $200 \mathrm{mM}$ betaine, respectively. (B) Screening of agents used to dissociate rHDAC1 aggregates. After incubation and filtration, samples were subjected to SDS-PAGE. Lane M: molecular mass marker; lanes 1-2: retentate and filtrate of untreated rHDAC1; lanes 3-12: retentate (odd lanes) and filtrate (even lanes) after incubation with SDS (2\%, lanes 3 and 4), Triton X-100 (1\%, lanes 5 and 6), Tween 20 (1\%, lanes 7 and 8), urea (1 M, lanes 9 and 10), $\mathrm{MgCl}_{2}(200 \mathrm{mM}$, lanes 11 and 12). (C) SDSPAGE of aliquots of retentate and filtrate samples separated by Amicon Ultracel (YM100). Lane M: molecular mass markers. Lanes 1 and 4: untreated rHDAC1. Lanes 2-3: rHDAC1 samples incubated with $0.2 \%$ SDS; lanes 5-6: rHDAC1 samples incubated with $0.05 \%$ SDS.

\section{FIGURE 4}

rHDAC1 activity assay. The release of $\left[{ }^{3} \mathrm{H}\right]$ acetic acid from $\left[{ }^{3} \mathrm{H}\right]$ acetyl histones was assayed at 37 ${ }^{\circ} \mathrm{C}$. Reaction mixtures containing 1.5 or $2.5 \mu \mathrm{g}$ of $\mathrm{rHDAC} 1$ were incubated for $2 \mathrm{~h}$; the reactions were then stopped, and the radioactivity associated with the release of $\left[{ }^{3} \mathrm{H}\right]$ acetic was estimated. Two control reaction mixtures (containing only buffer, and devoid of enzyme), were also assayed. One of these control reaction mixtures was also supplemented with $0.2 \%$ SDS (filled triangle). 

2

3

4 
A

$\begin{array}{lllll}\mathrm{kDa} & \mathrm{M} & \mathrm{NI} & 1 & 2\end{array}$

116

66

-

45

35

B

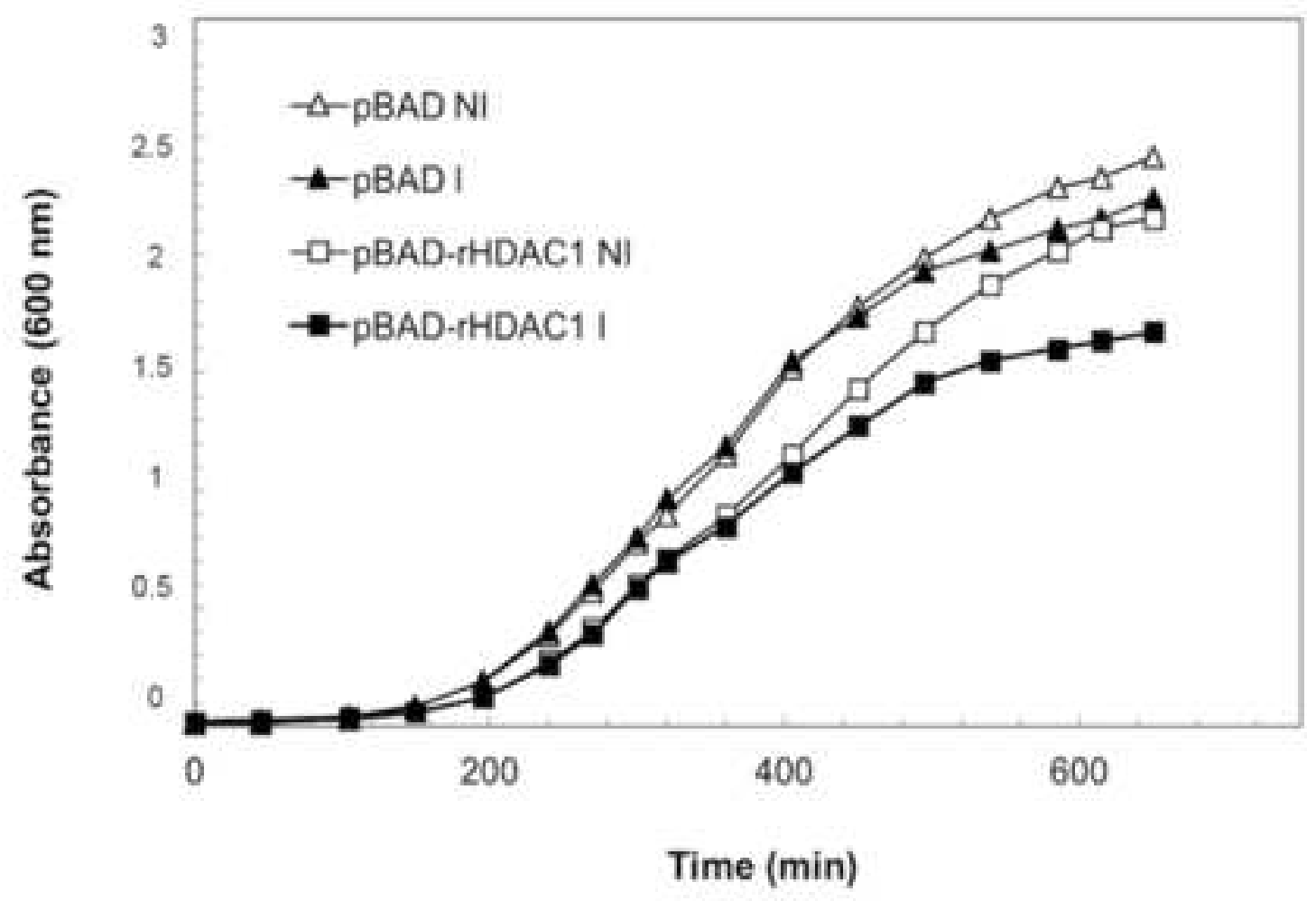


Figure 2

A

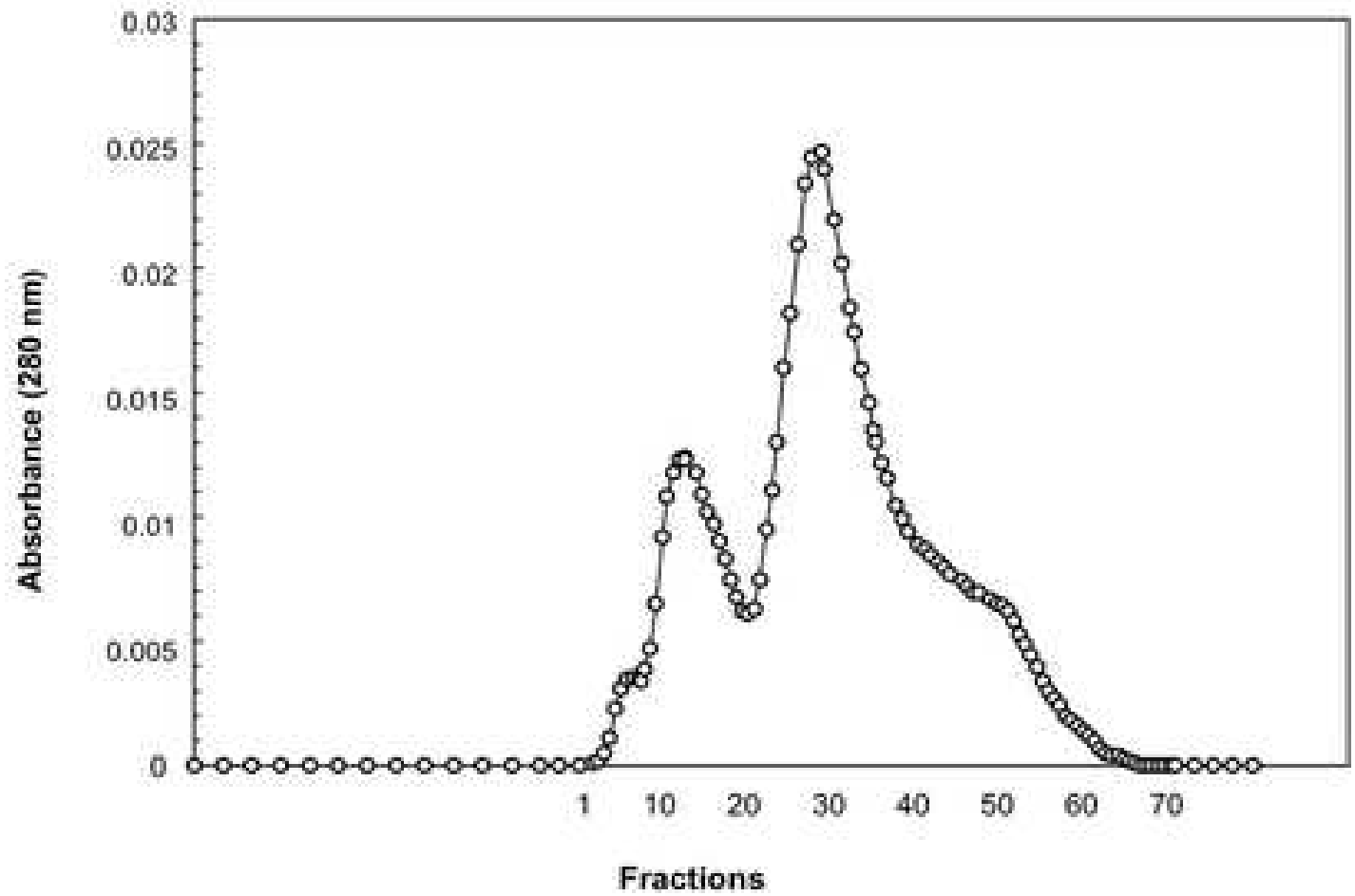

B

$\begin{array}{llllllllllllllllll}\mathrm{kDa} & \mathrm{M} & \mathrm{I} & 6 & 8 & 11 & 13 & 15 & 18 & 20 & 23 & \mathrm{M} & 26 & 28 & 32 & 40 & 44 & 53\end{array}$

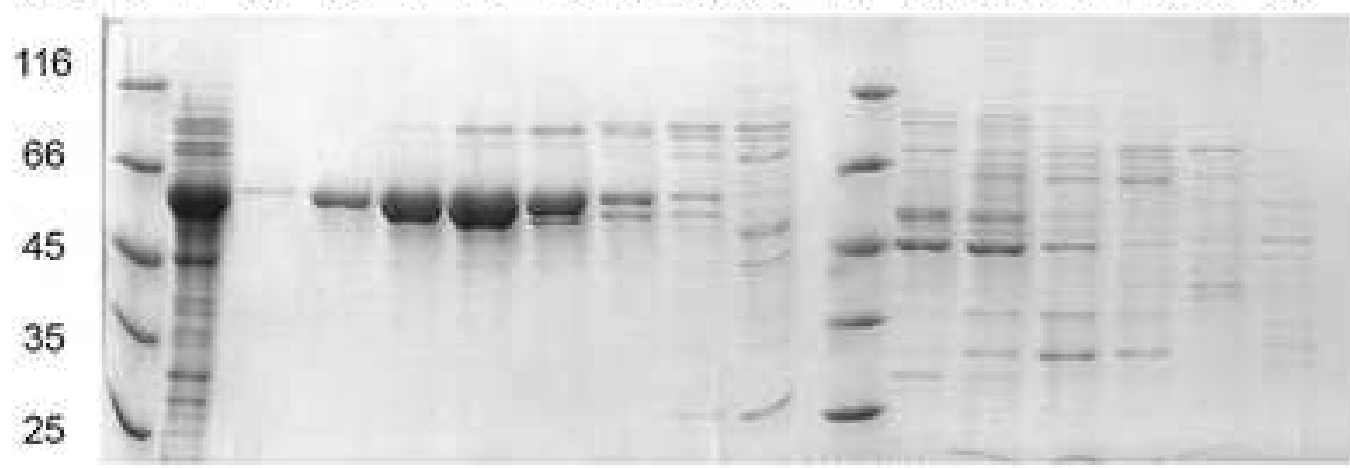

C

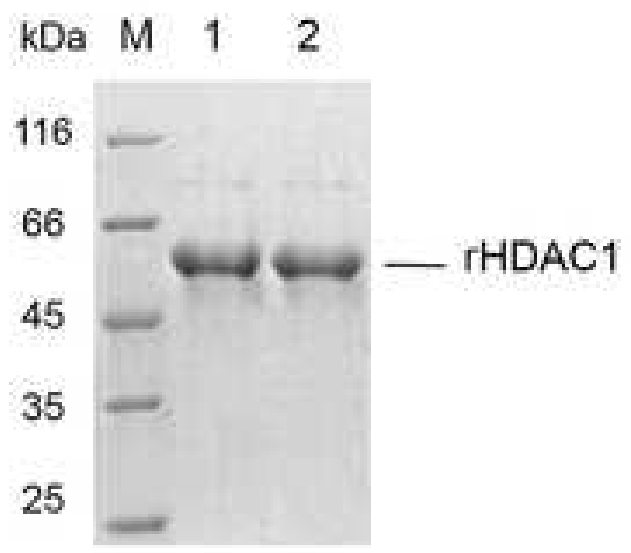


A

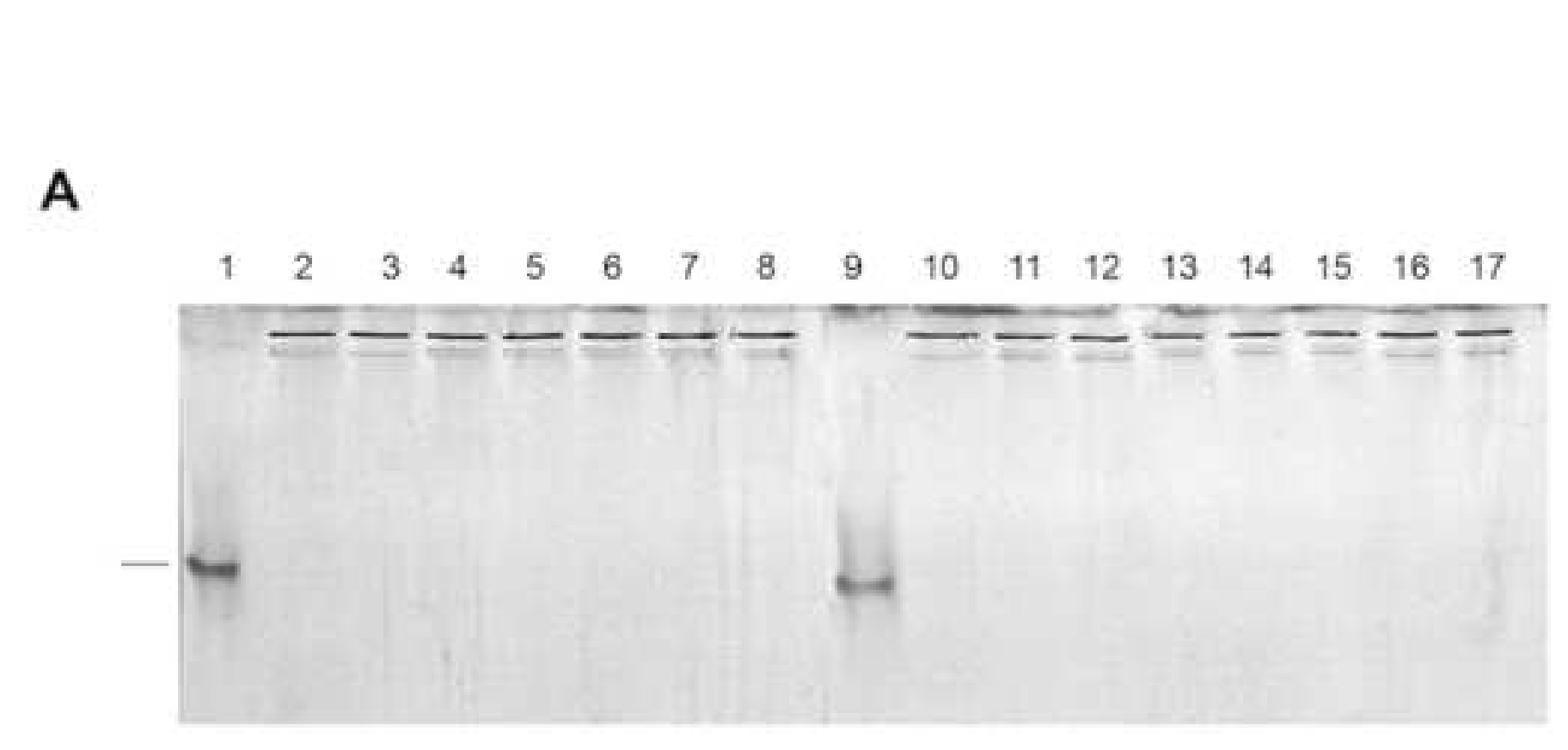

B

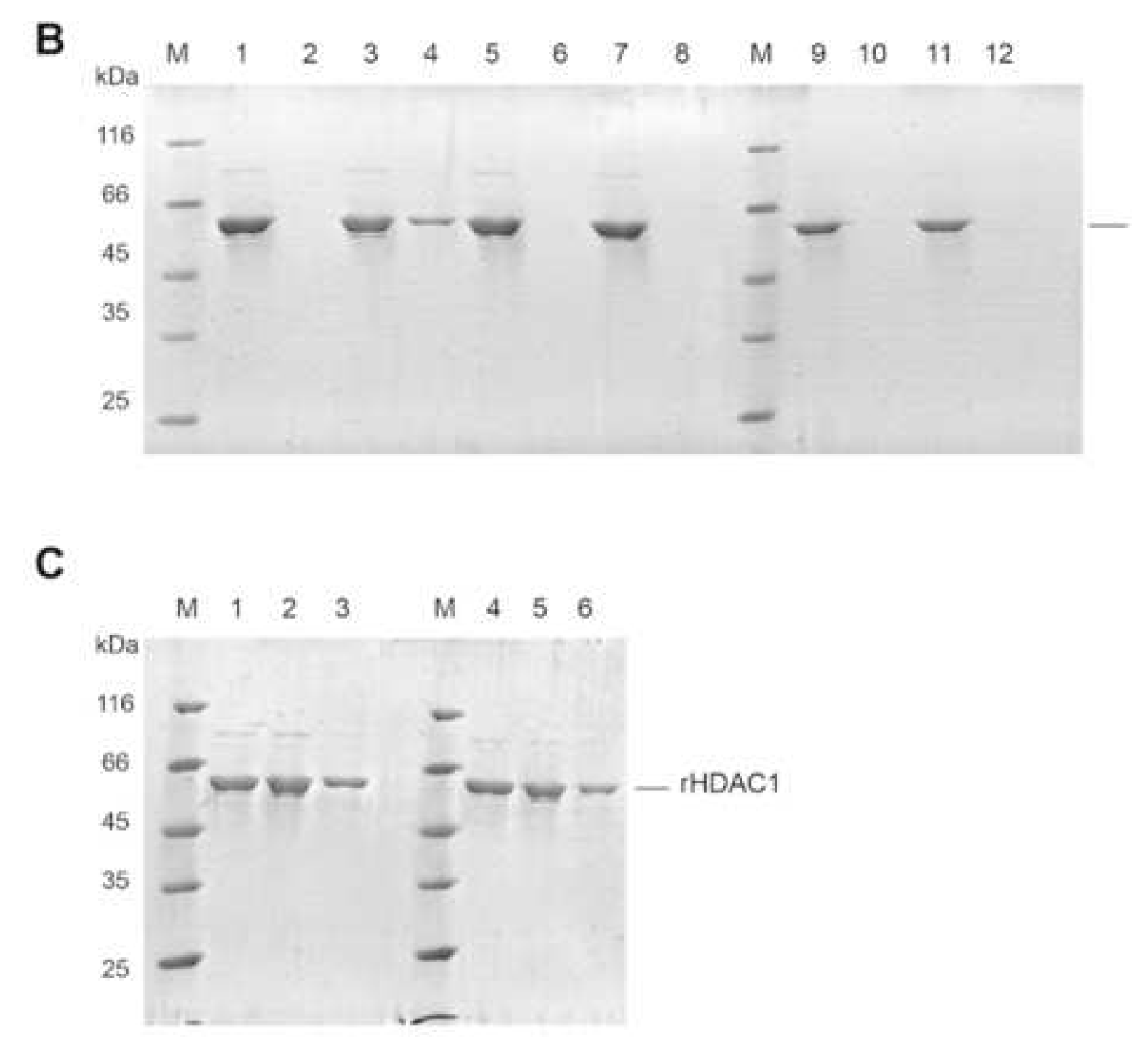

C

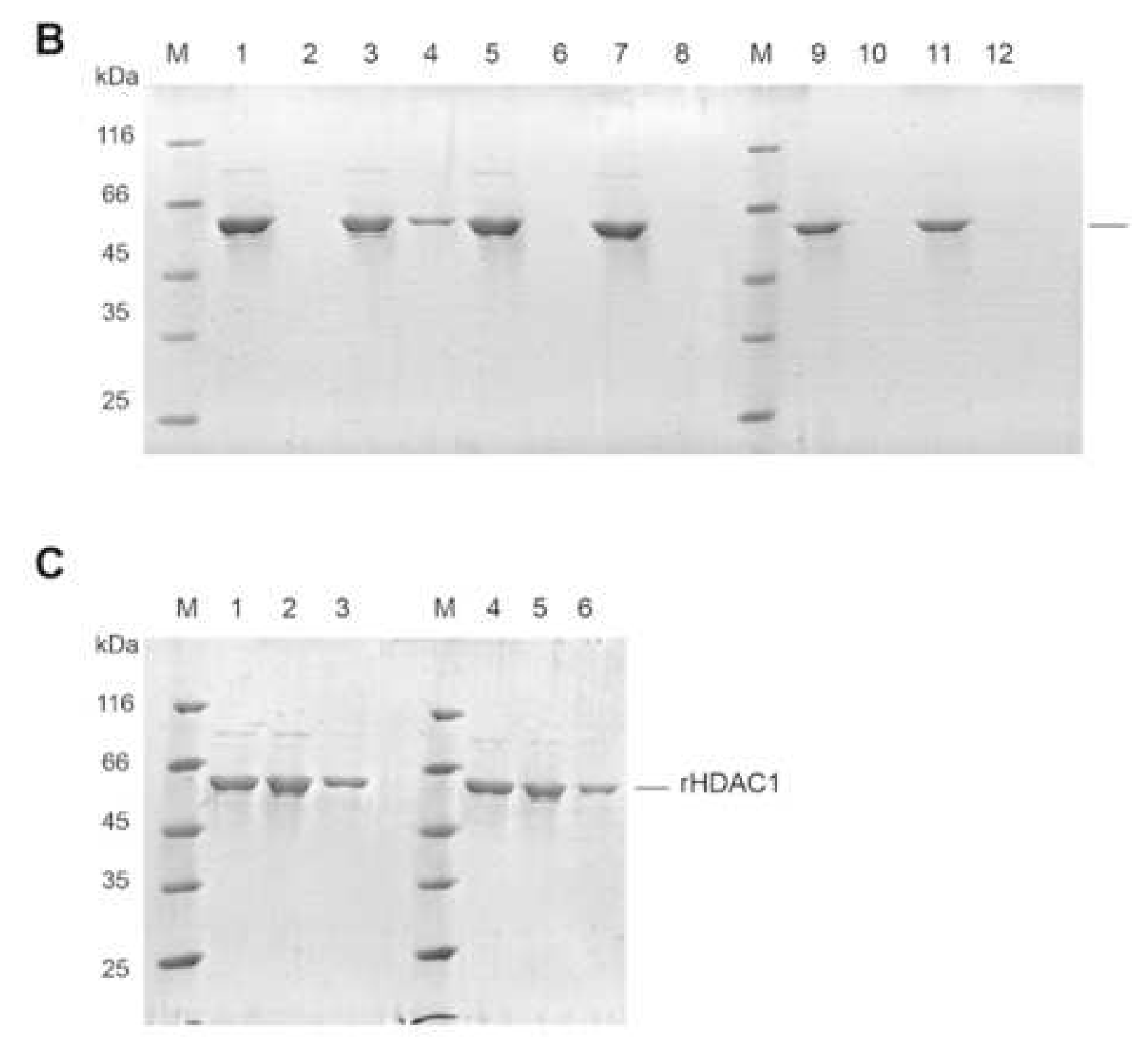

Figure 3
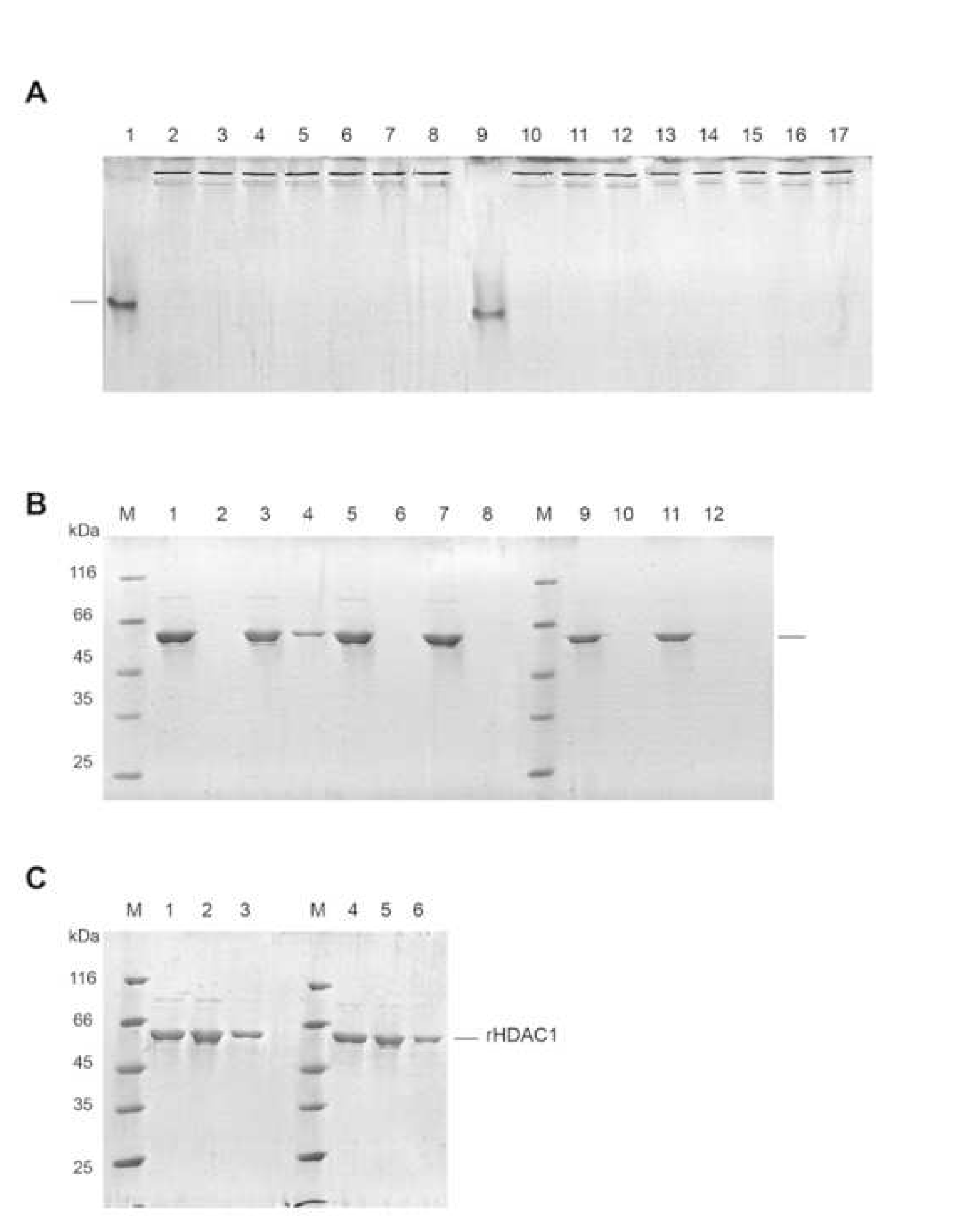


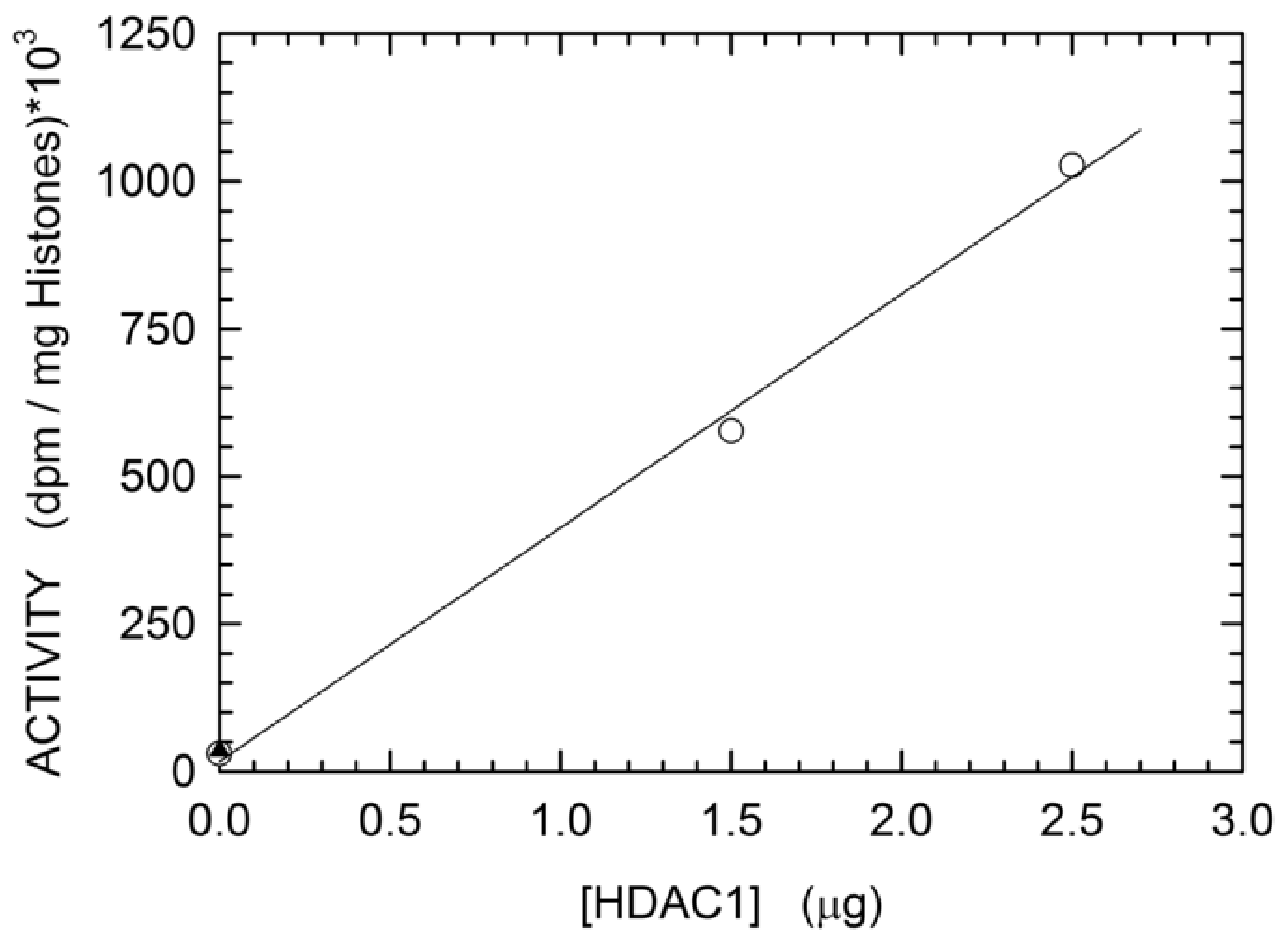


TABLE 1. Mass spectrometry data leading to the identification of HDAC1 peptides following in gel digestion of the purified protein. The mass/charge $(\mathrm{m} / \mathrm{z})$ ratio of the detected ions is indicated, along with the corresponding identified fragments (peptide) of HDAC1, whose detected (observed) and expected (theoretical) masses are reported in Dalton.

\begin{tabular}{ccccc}
\hline $\begin{array}{c}\text { Observed } \\
\text { ion }(\boldsymbol{m} / \mathbf{z})\end{array}$ & $\begin{array}{c}\text { Molecular mass } \\
\text { (observed) }\end{array}$ & Peptide & $\begin{array}{c}\text { Molecular mass } \\
\text { (theoretical) }\end{array}$ & $\begin{array}{c}\text { Difference } \\
\text { (ppm) }\end{array}$ \\
\hline 588.6564 & 2938.2556 & $11-34$ & 2938.2592 & -1.23 \\
626.3444 & 1876.0114 & $35-49$ & 1876.0141 & -1.46 \\
804.4219 & 1606.8292 & $37-49$ & 1606.8289 & 0.19 \\
579.3143 & 1734.9211 & $37-50$ & 1734.9239 & -1.63 \\
537.2816 & 1072.5486 & $51-58$ & 1072.5488 & -0.097 \\
638.9561 & 1913.8465 & $59-74$ & 1913.8465 & -0.013 \\
520.7377 & 1039.4608 & $67-74$ & 1039.4611 & -0.2 \\
476.2258 & 1425.6556 & $78-89$ & 1425.6558 & -0.15 \\
1079.8342 & 3236.4808 & $94-123$ & 3236.4795 & 0.39 \\
615.9831 & 1844.9275 & $127-143$ & 1844.9282 & -0.38 \\
828.113 & 2481.3172 & $144-165$ & 2481.3189 & -0.68 \\
1177.6198 & 2353.225 & $145-165$ & 2353.2239 & 0.48 \\
735.3841 & 2937.5073 & $145-169$ & 2937.5058 & 0.5 \\
893.4291 & 2677.2655 & $170-192$ & 2677.266 & -0.21 \\
482.7491 & 963.4836 & $193-200$ & 963.4848 & -1.2 \\
687.8198 & 1373.625 & $201-212$ & 1373.6252 & -0.098 \\
579.7999 & 1157.5852 & $221-229$ & 1157.5869 & -1.44 \\
800.637 & 3198.5189 & $221-247$ & 3198.5219 & -0.95 \\
1022.4819 & 2042.9492 & $230-247$ & 2042.9507 & -0.69 \\
1257.0758 & 2512.137 & $248-270$ & 2512.1396 & -1.03 \\
533.2903 & 1064.566 & $271-279$ & 1064.5688 & -2.63 \\
913.967 & 1825.9194 & $290-306$ & 1825.9219 & -1.34 \\
1117.0306 & 2232.0466 & $343-361$ & 2232.048 & -0.63 \\
1211.2098 & 3630.6076 & $372-404$ & 3630.609 & -0.39 \\
455.2207 & 908.4268 & $405-412$ & 908.4273 & -0.52 \\
579.2526 & 2312.9813 & $413-432$ & 2312.9815 & -0.084 \\
719.9678 & 2156.8816 & $414-432$ & 2156.8804 & 0.55 \\
492.8951 & 1475.6635 & $445-456$ & 1475.6627 & 0.52 \\
\hline & & & & \\
\hline
\end{tabular}


TABLE 2. Additives used to promote protein dissociation. The concentrations indicated are expressed as: $\%(\mathrm{v} / \mathrm{v})$ for detergents and alcohols, $\mathrm{mM}$ for salts, urea, and $\beta$-mercaptoethanol, and $\mu \mathrm{M}$ for fatty acids.

\begin{tabular}{lc}
\hline Reagent & Concentration \\
\hline Sodium dodecyl sulfate & 2 \\
Triton X-100 & 1 \\
Tween 20 & 1 \\
$\mathrm{KCl}$ & 500 \\
$\mathrm{LiCl}$ & 500 \\
$\mathrm{MgCl}_{2}$ & 200 \\
$\mathrm{CaCl}_{2}$ & 200 \\
$\mathrm{StCl}_{2}$ & 200 \\
Urea & 1000 \\
Arginine & 200 \\
Betaine & 200 \\
Glycine & 200 \\
Ethanol & 2 \\
2-propanol & 2 \\
1-butanol & 1.5 \\
1-pentanol & 0.6 \\
$\beta$-mercaptoethanol & 10 \\
Lauric acid & 200 \\
Myristic acid & 200 \\
Stearic acid & 200 \\
\hline
\end{tabular}

